\title{
Stone consolidation: a critical discussion of theoretical insights and
}

\section{field practice}

\author{
Ylenia Praticòo ${ }^{1}$, Francesco Caruso ${ }^{2,3}$, José Delgado Rodrigues ${ }^{4}$, Fred Girardet ${ }^{5}$, Enrico Sassoni ${ }^{6}$, George W. \\ Scherer ${ }^{7}$, Véronique Vergès-Belmin ${ }^{8}$, Norman R. Weiss ${ }^{9}$, George Wheeler $^{10}$, Robert J. Flatt ${ }^{1}$
}

\footnotetext{
${ }^{1}$ ETH Zürich, Institute for Building Materials, Physical Chemistry of Building Materials, Switzerland

${ }^{2}$ University of Oslo, Department of Archaeology, Conservation and History, Oslo, Norway

${ }^{3}$ Swiss Institute for Art Research (SIK-ISEA), Department of Art Technology, Zürich, Switzerland

${ }^{4}$ National Laboratory for Civil Engineering (LNEC), Materials Department, Lisbon, Portugal

${ }^{5}$ RINO Sàrl, Blonay, Switzerland

${ }^{6}$ University of Bologna, Department of Civil, Chemical, Environmental and Materials Engineering, Bologna, Italy

${ }^{7}$ Princeton University, Civil and Environmental Engineering, Princeton, NJ, United States

${ }^{8}$ Laboratory of Research on Historical Monuments (LRMH), Stone Conservation, Champs-sur-Marne, France

${ }^{9}$ Columbia University, Graduate School of Architecture, Planning and Preservation (GSAPP), New York, United States

${ }^{10}$ Highbridge Materials Consulting, Inc., Pleasantville, United States
}

\begin{abstract}
Stone consolidants have been extensively used for the preservation of historical structures since the 19th century. However, their true effectiveness in practice is often a source of debate, largely because of known cases where badly chosen treatments were unsuccessful, or even caused an accelerated degradation of the substrate. Researchers have therefore strived to better understand, and possibly predict, the behavior of consolidants on-site, in order to assist practitioners in their decision making. Despite the large number of publications available on the subject, however, the contribution of scientific research for practical applications remains scarce.

Reasons for this include the limited accessibility of scientific publications and the lack of documentation or preparatory studies from the field. This unfortunately compromises the knowledge exchange between researchers and practitioners, which we consider to be a main challenge that this field must overcome.

The target of this letter is to reconnect the critical problems identified on-site through practical experience with the conceptual research outcomes that could help solve them. For this, we present an informed evaluation of the most needed research, along with a synthetic overview of the insights that scientific research can offer in terms of consolidant selection, application and monitoring.

Keywords: Stone consolidants; Conservation; Testing; Compatibility; Guidelines
\end{abstract}

\section{Introduction}

Research on durability has been gaining importance in the building industry over the past decades. This has fostered the understanding of mechanisms of decay and has led to a boost in the research on products and methodologies for maintenance, which can also find application in the conservation of historical structures. Yet, as is often the case in interdisciplinary fields, the knowledge transfer between research and practice has been relatively disappointing for both sides [1].

The research community is generally pressured to provide "universal" results. Its outcomes are intended as a guide for the applicability and potential success of treatments, with the assumption that they reflect similar (or, possibly, improved) performances on-site, more or less regardless of how different the exposure conditions may be. It is however rare to see practitioners having the time or resources to follow up the information provided by research with site-specific systematic tests, to ensure the effectiveness and durability of their planned treatments [2]. The consequence is a divergence in the work of researchers and practitioners.

One of the targets of this letter is to help reconnect the inputs from both the research and the field on practice-relevant problems relating to stone consolidation. As a consequence,

* Corresponding author: Ylenia Praticò, Email: praticoy@ethz.ch 
we have structured the review around the following topics and related questions:

One of the targets of this letter is to help reconnect the inputs from both the research and the field on practice-relevant problems relating to stone consolidation. As a consequence, we have structured the review around the following topics and related questions:

1. Background: What is a consolidant, what should it do and when should it be used?

2. Some needs from practice: What are practitioners most concerned about? Is research addressing these issues sufficiently?

3. Some answers from research: What research outcomes can already be used to address current practical issues? What upcoming results should we look forward to?

4. Common ground for practitioners and researchers: How can better synergies be implemented between research and practice?

In doing this, we hope to give scientists an informed evaluation of the most needed research, and, at the same time, provide practitioners with an overview of the insights that research can already offer in terms of consolidant selection, application and monitoring. Hopefully, this will also motivate practitioners and researchers to engage in a higher level of discussion, to define essential research questions going beyond site- and case-specific issues. We believe that such a paper is timely and can help the field advance towards new horizons.

As a more general remark, many of the meta-challenges and strategies defined in this introduction, also apply to other areas of cultural heritage. To this end, readers interested in repair mortars may refer to a related RILEM report [3].

\section{Background}

The term consolidant (from Latin com- "together" + solidare "to make solid") is used to indicate a product that can restore strength to a degraded material. A consolidation treatment consists in the combination of a consolidant and the technique and conditions used to apply it. Hence, a single product may be involved in several consolidation treatment types. For a product to qualify as a consolidant, it must satisfy a number of prerequisites. It must be able to quickly, deeply and homogeneously enter the stone. The treated material must recover properties as similar as possible to the original substrate. Treatments are expected to be durable, not cause degradation, and not preclude the possibility of a different treatment with the same or another material in the future. Finally, consolidation products should be inexpensive and non-toxic.

Some of these requirements can be satisfied more easily than others. For instance, good penetration depth can be ensured by reducing the contact angle $(\vartheta)$ and the viscosity $(\eta)$ of the consolidant (also particle size distribution in the case of suspensions such as nano-limes [4,5] or particle modified consolidants [6]). However, because other requirements cannot be easily defined in terms of measurable material properties, practitioners prefer to define expectations with a set of specific terms [7].

Reversibility refers to the ability to remove a consolidant if this turns out to be necessary at any time after its application. It must not be confused with retreatability, which is the possibility to apply another product over the previous one, at later stages. Durability is the ability of the treatment to maintain its function over time, and thus to prolong the service life of the stone. Compatibility is a more ambiguous but crucial - concept that we will discuss separately in section 2.2. In short, it expresses the severity of possible drawbacks associated with the chosen treatment.

Each of the above terms embodies a large number of material properties. In section 3 , we will show how scientific research has tried to answer such needs.

\section{Some needs from practice}

Selecting the best consolidation treatment involves an optimization process among many different and sometimes contradictory requirements, ranging from material properties to ethical decisions and financial aspects $[8,9]$. In this section, we address questions that are of direct concern to conservation scientists and try to outline how conservation science and scientific research can contribute, with rational insight, into the overall and complex decision-making process needed for in situ application.

\subsection{To consolidate or not to consolidate?}

The first steps in a conservation campaign is to assess the state of conservation, including the kind of degradation types and their causes, decide on the actions needed and, in terms of consolidation, if and where to apply the consolidation treatment. Conservators must weigh cost-benefit ratios, where the cost is not only financial but also involves the risk of reducing the durability of the material, corrupting its authenticity, or erasing information it contains (see section 2.2). For this reason, it is important to act only when absolutely necessary, but also not postpone the intervention until the material has degraded too much for the consolidation to be beneficial.

A key question is hence: how does one draw the line between avoidable and urgent?

On the positive side, remarkable progress has been made in measuring the extent of degradation of the substrate in quantitative terms [10] and studies like "the ABC method" provide a solid basis to define a rational "urgency" rating-term [11]. However, attempts to directly relate this to an urgency and/or usefulness of consolidation remain rare [12].

\subsection{Is the treatment compatible with the substrate?}

While being one of the pillars of modern conservation, compatibility is a complex concept that the scientific community struggles to translate into measurable terms. Behind the term compatibility there is an effort to underline the need to preserve both "the historical and the aesthetical 
instances" of the object ${ }^{\mathrm{a}}$. In other words, this means that a treatment is compatible if it does not alter the appearance of the object of interest (hence the message conveyed remains "readable"), but also if it neither significantly alters nor damages the nature of the original material substrate, which carries a historical value in itself. To achieve this, the properties of the material after the treatment must match, as well as possible, the ones of the original substrate, both aesthetically (color, gloss) and physically (thermal expansion, strength, water and vapor transport, etc.). For the treatment to be considered compatible, discrepancies must be imperceptible to the eye and small enough to avoid inducing any degradation. However, defining the boundary between dangerous and negligible mismatches is difficult, as we discuss in section 2.2.1.

These concepts are similarly encompassed in the term harmfulness, so that this and compatibility are often considered interchangeable definitions. Having a broader interpretation, however, compatibility also is a characteristic of the treatment strategy itself, defining how realistic are the time, investments and skills required in the specific context. Additionally, a compatible treatment shall also not be harmful to the environment or constitute a health and safety hazard.

In summary, compatibility is invoked as an overall measure of the risks and drawbacks associated with a certain treatment. Given the many aspects involved, however, it is hard to establish a numerical measure of "degree of compatibility" and - de facto - treatments generally qualify as "fairly compatible" or "incompatible" on the basis of experience and good sense.

\subsubsection{Success versus Induced risks: where is the acceptable tradeoff?}

Deciding whether to perform a consolidation treatment forces one to decide whether the potential benefits are worth the drawbacks. Without a rational and recognized evaluation procedure for defining either the success or the incompatibility (or harmfulness) of a treatment, the liability for the choice fully weighs on the shoulders of the decision maker. To deal with this challenge, some researchers proposed methods to compute an "efficiency index" [14] as well as to quantify the "incompatibility risks" [15]. These approaches are promising in that they offer a tool to select the best possible treatment or mindfully decide to do nothing. Both methods, however, use some highly context-dependent input that can only be determined via preliminary laboratory and field evaluations. This means that such scores rely on methods over which there is often no consensus, and that are - in most cases - not exhaustive or not direct to the point [16]. The following two paragraphs review the two subjects of greatest concern: the validity of laboratory results for the actual consolidation practice (section 2.3) and the demand for more convenient methods for on-site assessment (section 2.4).

\subsection{Usability of laboratory test results}

Results obtained by laboratory testing are taken with a grain of salt by on-site practitioners. This is due to differences (or sometimes even lack of overlapping) between laboratory and on-site conditions that cast doubt on the direct transferability of the research findings to practical situations. The practices in laboratory testing of consolidation products more often criticized are [17]:

the frequent use of fresh stone samples, substantially dissimilar from the degraded substrate for which the treatment is needed;

- the evaluation of performance under environmental conditions never occurring on-site, whether too extreme or too constant throughout the test;

- the frequent adoption of application procedures that cannot be implemented on-site, due to either practical, safety or financial reasons.

Lab tests are designed in an effort to make them easily and ubiquitously reproducible, so that their results are comparable regardless of the time and place at which they are obtained. This drive to "universalizing" testing procedures contrasts with the site-dependent factors affecting the product performance, such as orientation, exposure and substrate condition. This does not mean per se that the conclusions from scientific studies are irrelevant to practitioners. However, a certain disconnect can result if research conditions are not sufficiently contextualized with respect to the reality of application conditions considered. At the same time, research must strive to reach conclusions of far-reaching significance. The risk is therefore to "overenthusiastically" present results as allegedly "universal" guidelines, when they may be based on too narrow or unrealistic conditions.

Some attempts have been made to develop methodologies that can combine research and case-specific testing for the support for product selection, yielding results that could simultaneously satisfy the interests of academia and the field [18-20]. Achieving this often appears as wishful thinking, especially because of the lack of standard tests equally approved by scientists and practitioners. Some researchers proposed a way around this, by customizing rational criteria to define laboratory testing conditions that best represent the critical conditions at the site of interest $[21,22]$. The appealing aspect of this approach is that it delivers durability results that are more directly useful to practitioners, while still relying on impartially chosen parameters. However, in view of being able to compare material performance over time and between projects, it should to be complemented by more 
standard tests with fixed conditions to create some sort of material performance baseline.

\subsection{The relevance of on-site assessment}

Despite the many advanced non-destructive techniques (NDTs) available today, and the strong desire from practitioners to obtain more information on the performance of consolidants in situ, systematic on-site assessments still remain rare [23]. Advanced techniques are rarely applied, and, if they are, require significant time and financial investments, as well as the presence of highly specialized operators [24]. A more effective option has been to build up networks of academics and specialists who offer conservation science services for practitioners [25]. This improves the situation, but does not resolve the problem that most often practitioners only have a narrow choice of field tests (see 2.4.1). Therefore, to promote on-site assessments as a regular step during and after the application of consolidants, more research should be dedicated toward developing affordable and simple, yet meaningful, methods that can be used routinely.

\subsubsection{Evaluation of effectiveness}

The term effectiveness is often used to define the "extent of success" of a treatment. This depends on many aspects, first and foremost on how the goals were defined (see section 4.1). For now, we assume effectiveness to be solely an indication of the ability of the consolidant to improve the stability of the substrate. Thus, some specific material properties can be used to measure it.

Changes in permeability, porosity and/or hydrophobicity can serve as indirect indicators of the presence and distribution of the consolidant regardless of its effect, while strength and hardness directly reflect the consolidation. Most often these properties cannot be measured on-site by means of NDTs, so that practitioners resort to "proxies" obtained from available simple field tests, such as scratch tests, brush tests, tape pulloff, water drop and the resonance pointer [26]. More rigorous approaches include imaging, ultrasonic or impact techniques. Yet, none of the above-mentioned NDTs offer enough information about the properties of the material beneath the surface. In this respect, the Drilling Resistance Measuring System (DRMS) seems to be the only method commonly adopted to obtain information on the depth of penetration into the substrate, despite the difficulties caused by its weight, geometry, partially destructive nature, and the need for several measurements to obtain robust results. It is also important to bear in mind that DRMS, like any other measurement of hardness or strength, is best performed after allowing the consolidant to cure for enough time ${ }^{b}$.
Conversely, DRMS can be useful while planning an intervention to determine the needed consolidation time and depth (see section 4). This can also serve to determine the minimum time during which scaffolding would ideally have to remain in place to correctly test the outcome of an intervention.

However, additional methods are needed to provide feedback during an ongoing consolidation campaign, for instance to assess the penetration depth of the product. Portable NMR devices have been developed in recent years and may find applications for such problems [30]. An invasive, but practical solution to this problem was proposed within the Stonecore project, where an ultrasonic device for depth profile measurements was developed [31].

\subsubsection{Medium- and long-term assessments}

A successful short-term consolidation offers no long-term guarantees. For this, the consolidant must not cause an accelerated degradation, in addition to maintaining the mechanical integrity of the treated stone as long as possible.

In practice, it is accepted that most consolidants lose their effectiveness over time and that additional treatments will be needed at a later stage. From a philosophical point of view, this has a certain appeal since it means that the consolidant, while not reversible, is also not eternal. From a practical point of view, it raises the question of when this additional treatment should be applied.

It has to be noted that long-term deterioration directly caused by consolidation treatments may occur without any significant degradation of the consolidant itself, often due to excessive hardening or reduced permeability of the consolidated zone. Such effects are better designated as delayed harmfulness, rather than loss of effectiveness.

Long-term performance assessments require the planning of regular visits after the treatment and demand persistent commitment. This is rarely the case, and results in a lack of data about long-term consolidation performance (and the performance of conservation treatments on cultural heritage more generally). For those cases where monitoring is done, a simple but useful comparative strategy has been suggested by Laurenzi Tabasso and often adopted in the past decades. It consists in leaving an untreated patch as a reference point to be compared to the rest of the treated zones [32]. Despite the usefulness of this simple approach, issues remain about which methods should be employed to obtain more objective measurements of the consolidated areas over time.

Measurement of the remaining consolidation efficacy as well as the early detection of induced degradation are challenged not only by the lack of adequate NDTs, but also by the
${ }^{\mathrm{b}}$ Especially in the case of ethyl-silicate based consolidants, it has been
shown that environmental conditions can have a large influence on the
curing time (i.e., the time needed to reach full hardening), lengthening it
in some cases to up to three months. In such cases, a measurement of the
elastic modulus after four weeks would underestimate the consolidation
by about 50\% [27]. Preliminary laboratory studies could serve to determine the minimum time during which scaffolding should remain in place to test the outcome of the intervention. Recent studies have shown that curing of ethyl silicate is greatly accelerated by post-treatment with a water/alcohol solution [28,29]. 
reduction in accessibility once scaffolding is removed. Strategies for the long-term monitoring of historical structures should therefore be developed that borrow approaches used in studies of durability of built structures, where targeted embedded sensors or instrumented robots or drones for regular checkups are being developed [33-35].

\section{Some answers from research}

Many of the questions raised by conservation practice can currently find an answer in the scientific literature. However, the usability of these results is hindered by the inherently scattered nature of scientific publications. In this section, we will try to summarize the most significant findings and the most promising, partially still ongoing scientific research for a list of problematic issues normally encountered in conservation practice.

\subsection{Change in transport properties}

A consolidant inevitably affects to some degree the liquid water and water vapor transport properties of stone. Characterizing such changes is of great concern since large changes of these properties are generally considered to be undesirable. From a pragmatic point of view, and omitting a more detailed discussion on the consequences of changing transport properties after consolidation, we can assume that a "safe objective" would be for consolidation to only have a limited impact. It must however be kept in mind that the effect of any treatment is strongly substrate- and application method- dependent. Therefore, case-specific evaluations should also be recommended.

Fortunately, the physics behind water and vapor transport is well known, and depends only on a few parameters, which reduces but does not eliminate the need for time-consuming and costly testing. For example, it is known that vapor transport is dominated by the pore geometry, so that we expect a consolidant to affect such transport if it coats or partially fills this porosity. In practice, this means that resins would clearly reduce vapor transport and that their impact should be assessed. In contrast, ethyl silicates would be expected to have a much lower impact on vapor transport ${ }^{c}$.

Liquid water transport also depends on pore geometry. Large pores take up water faster, but to lower heights (in vertical rise cases), while small pores lead to slower ingress, but greater heights of capillary rise. However, in terms of liquid transport, the chemical nature of the consolidant plays a bigger role than in vapor transport, because it affects the wetting angle and, as a consequence, the sorptivity. Consolidants that increase the contact angle of water with the treated stone decrease its capability to transport liquid water. This may force water to evaporate behind the treated zone and can eventually lead to local water accumulation that might enhance freezing or salt crystallization damage.

\subsection{Adhesion and cracking}

The effectiveness of a consolidation treatment is strongly influenced by how well the consolidant adheres to the substrate. This is determined by: the chemical affinity of the consolidation product with the surfaces of the minerals constituting the substrate; the morphology of the hardened consolidant at the interface ("hooking" onto the substrate); and the mechanical capability of the consolidant-mineral interface to allow a distribution of shrinkage stresses, thus preventing the detachment of the consolidant from the substrate.

From the chemical point of view, one can roughly group consolidants according to their selective affinity to either silicate or carbonate stones. Alkoxysilanes only adhere well on the hydroxyl group-rich surfaces of silicate minerals, while lime-, barium hydroxide-, calcium phosphate- and oxalateand tartrate-based treatments are most effective on carbonate substrates [37]. Coupling agents can also be used to functionalize the surface to receive otherwise chemically incompatible treatments. In particular, amino-functional silanes and ammonium hydrogen tartrate have been historically used to add hydroxyl groups to the surface of carbonate stones, thus making them treatable with alkoxysilane treatments [38]. Polymeric resins, on the other hand, can be modified to offer a greater compatibility with different types of substrates, due to the broad range of their chemistry.

As mentioned above, however, these considerations regarding surface chemistry are not sufficient to predict the quality of adhesion. The mechanical interlocking with the substrate, and the ability of the treatment to bridge loose grains in the substrate or fill micro-cracks are also essential for obtaining an effective treatment.

The physico-mechanical properties of the treatment may also be improved by minimizing the cracking of the consolidant upon hardening. From a materials science point of view, this would require that the thickness of the deposited layer is lower than a critical value (characteristic of each product, depending on their intrinsic mechanical properties). This is especially relevant in the case of brittle consolidants such as the alkoxysilanes, and can be achieved, for instance, by varying the concentration of the active ingredients [39]. Another approach to prevent cracking is reducing the capillary pressure gradient during drying. This is done by decreasing the evaporation rate through inclusion of additives in the starting products [40]. In some cases, however, the above-mentioned arguments may be irrelevant. Indeed, cracking is not expected for polymeric consolidants or treatments (such as epoxy resins) that expand or show no volume change as they harden. Also, drying stresses are not expected to be significant for consolidants 
that form a discontinuous layer, as sometimes observed with nano-limes. In any case, the complexity of the characteristics of the substrate will play a key role on the final bond between the consolidant layer and the substrate. Among the most important characteristics are: roughness, pore geometry, orientation of the mineral phases exposed, and presence of water and soluble salts [41]. Such aspects are far from what a practitioner should be able to assess on-site, but represent levers through which researchers can try to improve consolidants. Regarding current field applications, it is nevertheless of vital importance to stress the need for preliminary testing in the laboratory, to correctly tune the properties of the chosen product for each specific stone substrate (see section 4) and decay profile [42].

\subsection{Conditions of application and curing}

As previously mentioned, the success of a given consolidation treatment depends on several factors: the penetration depth of the consolidant, its distribution in the pore system, as well as the thickness of the consolidant layer or deposit. All of these are strongly affected by the method of application, but also by the conditions of the substrate immediately before application and during the curing period [43]. For this reason, several studies have focused on testing the performance of different products by varying such parameters. Despite the reasonable skepticism about the applicability of the results of such tests outside of the specific conditions of the experiments performed, this type of research can offer general indications on what issues one should mostly worry about, for different types of products.

For instance, alkoxysilanes vary in performance due to the water content of the substrate (see also footnote 1), as an excess of water would accelerate the condensation reaction and hence influence the distribution of the product in the porous network [44]. Phosphate-based treatments, on the other hand, are most vulnerable to the presence of salts, as they can lead to the formation of phases of calcium phosphate more soluble than hydroxyapatite (the most stable calcium phosphate) [45]. Effectiveness of consolidation by barium hydroxide is most sensitive to the time allowed for its reaction with the resident calcium carbonate before carbonation occurs and, therefore, the application conditions are critical [46].

More detailed predictions about the on-site performance cannot be offered without taking into consideration the specificity of the substrate (even for different zones on the same facade!) and the several factors varying simultaneously during a real application campaign (skill of the operator, climate, actual amounts applied). This can lead to an excessive number of experiments being required, unless statistical tools are used to select the minimum number of experiments needed to achieve the maximum amount of information. For example, some studies have shown that the statistical approach given by the Design of Experiment (DOE) [47] can be a powerful tool in such cases, as it offers the possibility to predict the outcomes for systems with complex multi-factor interactions in a given range, using only a limited number of experiments [27].

\subsection{Effect of salt contamination on consolidation success}

Salts are considered to be one of the most important causes of damage in building stones. The damage mechanism develops through crystal growth in the pore network of these materials, leading to stresses that damage the stone. Depending on their solubility, salts can be transported and redistributed over a significant depth in stone, thus potentially affecting the consolidation action even if their amounts have previously been reduced by desalination [41]. While much attention has been paid to the possible negative effect of salts on the durability of consolidants, few studies have looked systematically at their influence on the effectiveness of consolidation itself $[48,49]$.

The impact that salts may have on the chemical reactions involved in the consolidation process depends on the nature of the consolidant and the solvent with which it is applied, as this will determine whether salts may dissolve or not. Independently, the presence of salt crystals may also limit the contact surface between the consolidant and the pore walls, which would reduce their performance. That issue would be exacerbated if the salts later dissolve in the presence of water, leaving behind gaps in the consolidated zones. Tests made on the consolidation of salt laden specimens have shown that a few cycles of water flushing through the consolidated specimens may almost completely eliminate the consolidation action of some ethyl silicates [50]. It is also worth mentioning that many ethyl silicates will lead to a temporary hydrophobicity of unpredictable duration after treatment. This affects water transport and thereby also salt damage. However, the way in which this will manifest itself needs to be evaluated from case to case.

\subsection{The influence of biofilms}

Biofilms are generally identified as a concern in relation to the performance of consolidation interventions. However, as with salts, there are little to no systematic data about whether or to what extent this really is an issue that we should be concerned with. What is generally stated is that a prior cleaning treatment, typically by means of commercial biocides or cultures of viable bacteria, is recommended [51]. It should be emphasized that the consolidant should mainly be within the stone and that, unlike salts, biofilms are mainly (but not exclusively) found on the outer surface of the stone. As a consequence, biofilms are typically not expected to interfere with the consolidation action in the core of the material, but can potentially hinder the penetration of consolidating products by blocking pores at or near the surface. This issue deserves more investigation with the development of adequate sample preparation and testing methodology being a high priority. In cases where removal of such films may be considered necessary, care must be taken to avoid damaging the substrate in this process.

\subsection{Dealing with clay-bearing stones}

Clay-bearing stones - especially those with a high content of swelling clays - can be weak materials that tend to need 
frequent conservation and may be particularly susceptible to cycles of wetting and drying [52-55]. Related studies of this phenomenon provide a good basis for investigating more specifically their interference with consolidation.

The presence of clays does not dramatically influence the characteristic penetration or adhesion of ethyl silicates in different stone types. Rather, it can even have a beneficial effect on limestones, as the clays provide hydroxyl groups for the TEOS-based consolidants to bind to [44].

However, when subjected to wetting/drying, most of the consolidation benefit offered by ethyl silicate can be lost within just a few cycles [55]. This is because alkoxysilanes are typically brittle once cured, and hence unable to withstand stresses exerted by clays. As a possible solution to this issue, swelling inhibitors have been proposed as a pre-treatment and preliminary results suggest that they can indeed extend the service life of TEOS-based consolidants $[56,57]$.

A negative effect of clays on the consolidation with other types of products has not been highlighted in the literature as of now. Nevertheless, clay-bearing stones often exhibit anisotropic behavior and a consolidation treatment may exacerbate such behavior and induce damage at medium or long term.

\section{Common ground for practitioners and researchers}

Several parts of this paper emphasize the importance of the connection between the work of the scientist and the conservator. As explained, researchers are able to a large extent to provide the information necessary to ensure a successful execution of a treatment. On the other hand, the direction of scientific research itself should better incorporate the experience of conservators, who have a good sense of the potential issues relating to application and real site conditions. In this respect, preliminary collaborative studies and dialogue are vital to conservation science, as they represent the occasion for practitioners and scientists to define questions of common interest.

\subsection{The importance of preliminary assessments}

The choice of a treatment always involves a certain degree of uncertainty, and the most established products, or those currently most frequently employed, are not necessarily the most appropriate. Preliminary assessments are important means to identify specific problems and to encourage consideration of lesser known, possibly more suitable treatment strategies. To achieve this, the following factors are worth characterizing:

- Nature of the substrate and preferably also its composition;

- Morphology of the porosity and cracks;

- Type and depth of deterioration and its causes;

- Type of consolidation needed (fill cracks or restore cohesion);

- Actual moisture content;
- $\quad$ Amount and type of salt contamination;

- Presence of bio-contamination and if so its nature;

- Specific conditions for treatment application (environmental conditions, accessibility);

- Conditions to which the consolidant will be subjected (potential degradation of the consolidant);

The knowledge of these aspects can be used to narrow down the list of suitable treatments $[9,42]$. For some problems, however, an answer may not yet exist. It is at this moment that preliminary assessments turn into an important opportunity for practitioners to define questions, and for scientists to take up the challenge to work in this unexplored but relevant territory.

\subsection{Pre-testing}

Whether a traditional or a novel product is considered for a treatment, it is of utmost importance to test consolidants before they are applied on an object of cultural interest. The strategy must be adapted case by case to ensure that the targeted effects are reached. In particular, reaching the necessary depth of penetration is essential.

The documentation on pre-testing of products is unfortunately very limited. However, it is possible to find examples of good on-site practice. Some case studies have been reported where the depth of the degraded layer was characterized by core drills taken at different locations on the facade of monuments [58]. The same specimens were then used to evaluate which application method needed to be used for the chosen treatment to reach the necessary penetration depth and, at the same time, avoid runoff of excess product. This strategy not only allowed for predefining the protocol of application, but also provided practitioners with a better estimation of the costs by evaluating the quantity of consolidant needed.

In many situations, it may not be possible to obtain cores. In such cases, other techniques should be considered (see section 2.4), and mock samples can be used in the laboratory for the optimization of the treatments $[59,60]$.

\section{Conclusions}

This letter began by suggesting that the dialogue between research and practice in the field of stone consolidation needs to be improved. The review of the current trends and practices showed that indeed some misalignments exist between the work of scientists and conservators. The picture depicted, however, anticipates a more positive future.

In section 2, we reviewed some of the unanswered questions that still exist in the on-site practice, suggesting a list of possible research lines that scientists ought to take up. In section 3, we examined the solutions that research already provides, grouping them by the on-site problems that they address. Finally, in section 4, we identified the preliminary assessment as an important node, where direct exchanges between research and on-site practice should take place.

In summary, all of the necessary elements for a fruitful dialogue between research and practice in stone 
consolidation seem already to be present. So, why does it appear to be so difficult for scientists and conservators to understand each other's work? On the one hand, the lack of detailed documentation of case studies hinders the ability of researchers to comprehend the issues that are encountered on-site. On the other, the many scientific works (most often accessible only upon subscription to scientific journals) make it practically impossible for practitioners to look up potential solutions to their issues. It is clear that more efforts should be put into making research more readable and easily accessible, and care should be taken to make the main conclusions of scientific studies directly transposable to conservation practice via specifically oriented documents and articles.

While investigating possible strategies to ensure correct treatment choices, Searls, in 1997, wrote "Sometimes the need is not for further research, but for the dissemination of existing knowledge" [61]. Now, more than ever, the rapid growth of open access journals is opening up a bright future for interdisciplinary conversations. This may be the right moment to rethink the way research in conservation science is presented, to find ways to reorganize laboratory results into more navigable resources [9], and to start awarding prestige to articles and documents that try to translate "hard" scientific data and conclusions into operational guidelines and recommendations.

\section{References}

[1] S. Muñoz Viñas, Contemporary Theory of Conservation. Routledge. 2005.

[2] H. R. Sasse, R. Snethlage, Methods for the Evaluation of Stone Conservation Treatments. In: Sav our Archit Herit Conserv Hist Stone Struct Rep Dahl Workshop Sav our Archit. Heritage-Conservation Hist Stone Struct. Berlin March 3-8 1996. John Wiley \& Sons, Ltd, 1997 223-243.

[3] K. Van Balen, I. Papayianni, R. Van Hees, L. Binda, A. Waldum, Introduction to Requirements for and Functions of Properties of Repair Mortars in Characterisation Old Mortars Respect Their Repair SoA Rep. RILEM TC 167-COM - November 2004 (Eds: C. Groot, G. Ashall, J. Hughes). RILEM Publications (Bagneux, France), 2007, 151160.

[4] C. Rodriguez-Navarro, E. Ruiz-Agudo, Nanolimes: From Synthesis to Application. Pure Appl Chem (2018) 90 (3): 523-550. https://doi.org/10.1515/pac-2017-0506

[5] G. Borsoi, Nanostructured Lime-Based Materials for the Conservation of Calcareous Substrates. ABE Archit Built Environ (2017) (8): 1-200.

[6] E. Aggelakopoulou, P. Charles, M. E. Acerra, A. I. Garcia, R. J. Flatt, G. W. Scherer, Rheology Optimization of Particle Modified Consolidants. MRS Online Proc Libr (2002) 712: II2.6.1-II2.6.6. https://doi.org/10.1557/PROC-712-II2.6

[7] R. Snethlage, K. Sterflinger, Stone Conservation in Stone Archit Prop Durab (Eds: S. Siegesmund, R. Snethlage). 5th ed Springer-Verlag (Berlin Heidelberg), 2014. https://doi.org/10.1007/978-3-642-45155-3 7

[8] P. A. T. I. Burman, "Hallowed Antiquity": Ethical Considerations in the Selection of Conservation Treatments. In: Sav our Archit Herit Conserv Hist Stone Struct Rep Dahl Workshop Sav our Archit. Heritage-Conservation Hist Stone Struct. Berlin March 3-8 1996. John Wiley \& Sons, Ltd, 1997, 269-290.

[9] J. Turk, A. Mauko Pranjić, A. Hursthouse, R. Turner, J. J. Hughes, Decision Support Criteria and the Development of a Decision Support Tool for the Selection of Conservation Materials for the Built Cultural Heritage. J Cult Herit (2019) 37: 44-53. https://doi.org/10.1016/j.culher.2018.10.001

[10] B. Fitzner, K. Heinrichs, D. La Bouchardiere, Damage Index for Stone Monuments in Prot. Conserv. Cult. Herit. Mediterr. Cities (Eds: E. Galan, F. Zezza). Swets \& Zeitlinger (Lisse, The Netherlands), 2002, 315-326.
[11] S. Michalski, J. L. Pedersoli, The ABC Method: A Risk Management Approach to the Preservation of Cultural Heritage. Ottawa, Canada: Canadian Conservation Institute. 2016.

[12] P. A. Warke, J. M. Curran, A. V. Turkington, B. J. Smith, Condition Assessment for Building Stone Conservation: A Staging System Approach. Build Environ (2003) 38 (9): 1113-1123. https://doi.org/10.1016/S0360-1323(03)00085-4

[13] C. Brandi, G. Basile, Theory of Restoration. Nardini ed. Istituto Centrale Per II Restauro (Roma, Italy). 2005.

[14] P. Theoulakis, I. Karatasios, N. A. Stefanis, Performance Criteria and Evaluation Parameters for the Consolidation of Stone in EU-ARTECH Symp Stone Consol Cult Herit- Res Pract Access, Research And Technology For The Conservation Of The European Cultural Heritage (Eu-ARTECH) (Lisbon, Portugal), 2008, 279-288.

[15] J. Delgado Rodrigues, A. P. Ferreira Pinto, M. Van Bos, Methods and Approaches in Stone Conservation: Analysis of an Enquiry in 10th Int Congr Deterioration Conserv Stone Prepr ICOMOS Sweden 2, 2004, 691-698.

[16] J. Delgado Rodrigues, A. Grossi, Indicators and Ratings for the Compatibility Assessment of Conservation Actions. J Cult Herit (2007) 8 (1): 32-43. https://doi.org/10.1016/i.culher.2006.04.007

[17] M. Laurenzi Tabasso, S. Simon, Testing Methods and Criteria for the Selection/Evaluation of Products for the Conservation of Porous Building Materials. Stud Conserv (2006) 51 (sup1): 67-82 https://doi.org/10.1179/sic.2006.51.Supplement-1.67

[18] V. Fassina, CEN/TC 346 - Conservation of Cultural Heritage: Working Group 3. 2016.

[19] W. S. Ginell, D. Wessel, C. L. Searls, Standard Guide for Selection and Use of Stone Consolidants. ASTM International (West Conshohocken, PA). 2008.

[20] G. A. Sleater, Stone Preservatives: Methods of Laboratory Testing and Preliminary Performance Criteria. Department Of Commerce, National Bureau Of Standards, Institute For Applied Technology, Center For Building Technology (Washington D.C., US). 1977. https://doi.org/10.6028/NBS.TN.941

[21] B. Lubelli, V. Cnudde, T. Diaz-Goncalves, E. Franzoni, R. P. J. van Hees, I. Ioannou, B. Menendez, C. Nunes, H. Siedel, M. Stefanidou, et al., Towards a More Effective and Reliable Salt Crystallization Test for Porous Building Materials: State of the Art. Mater Struct (2018) 51 (2): 55. https://doi.org/10.1617/s11527-018-1180-5

[22] Y. Praticò, F. Girardet, R. J. Flatt, Strategies for the Conservation of Built Heritage Based on the Analysis of Rare Events in Proc 13th Int Congr Conserv Deterioration Stone (Paisley, Scotland), 2016.

[23] J. Delgado Rodrigues, Consolidation of Decayed Stones. A Delicate Problem with Few Practical Solutions. Hist Constr (2001): 3-14.

[24] H. Svahn, Non-Destructive Field Tests in Stone Conservation Literature Study: Final Report for the Research and Development Project. Riksantikvarieämbetet (Stockholm). 2006.

[25] "Iperion available http://technologies.c2rmf fr/labstech/index php /accessed 2020)

[26] C. Bläuer, C. Franzen, V. Vergès-Belmin, Simple Field Tests in Stone Conservation in Proc 12th Int Congr Deterioration Conserv Stone NY, 2012.

[27] Y. Praticò, F. Caruso, T. Wangler, R. J. Flatt, Statistical Analysis at the Service of Conservation Practice: DOE for the Optimization of the Consolidation Procedure in Proc 13th Int Congr Conserv Deterioration Stone (Paisley, Scotland), 2016.

[28] S. Naidu, C. Liu, G. W. Scherer, Hydroxyapatite-Based Consolidant and the Acceleration of Hydrolysis of Silicate-Based Consolidants. J Cult Herit (2015) 16 (1): 94-101. https://doi.org/10.1016/j.culher.2014.01.001

[29] E. Franzoni, G. Graziani, E. Sassoni, TEOS-Based Treatments for Stone Consolidation: Acceleration of Hydrolysis-Condensation Reactions by Poulticing. J. Sol-Gel Sci. Technol. (2015) 74 (2): 398-405. https://doi.org/10.1007/s10971-014-3610-3

[30] B. Blümich, F. Casanova, J. Perlo, S. Anferova, V. Anferov, K. Kremer, N. Goga, K. Kupferschläger, M. Adams, Advances of Unilateral Mobile NMR in Nondestructive Materials Testing. Magn Reson Imaging (2005) 23 (2): 197-201. https://doi.org/10.1016/i.mri.2004.11.058

[31] M. Drdácký, Testing Efficiency of Stone Conservation Treatments in Adv. Mater. Conserv. Stone (Eds: M. Hosseini, I. Karapanagiotis). Springer International Publishing (Cham), 2018, 175-184. https://doi.org/10.1007/978-3-319-72260-3 8 
[32] . Laurenzi Tabasso, Products and Methods for the Conservation of Stone: Problems and Trends in 10th Int Congr Deterioration Conserv Stone, 2004, 269-282.

[33] D. Lattanzi, G. Miller, Review of Robotic Infrastructure Inspection Systems. J Infrastruct Syst (2017) 23 (3): 04017004.1-04017004.16. https://doi.org/10.1061/(ASCE)IS.1943-555X.0000353

[34] Y. Seguí Femenias, Electrochemical Durability Monitoring in Reinforced Concrete, Doctoral Thesis, ETH Zurich 2017.

[35] D. Gonzalez-Aguilera, 27th CIPA International Symposium 2019: Documenting the Past for a Better Future. XLII-2/W15. International Society for Photogrammetry and Remote Sensing (ISPRS). 2019.

[36] C. Hall, W. D. Hoff, Water Transport in Brick, Stone and Concrete. CRC Press. 2011.

[37] E. Hansen, E. Doehne, J. Fidler, J. Larson, B. Martin, M. Matteini, C. Rodriguez-Navarro, E. S. Pardo, C. Price, A. de Tagle, et al., A Review of Selected Inorganic Consolidants and Protective Treatments for Porous Calcareous Materials. Stud Conserv (2003) 48 (sup1): 13-25. https://doi.org/10.1179/sic.2003.48.Supplement-1.13

[38] G. Wheeler, J. Mendez-Vivar, E. S. Goins, S. A. Fleming, C. J. Brinker, Evaluation of Alkoxysilane Coupling Agents in the Consolidation of Limestone in Proc. 9th Int Congr Deterioration Conserv Stone, Venice June 19-24 2000 (Ed: V. Fassina). 2. Elsevier Science, 2000, 541-545.

[39] G. W. Scherer, G. S. Wheeler, Silicate Consolidants for Stone. Key Eng Mater (2009) 391: 1-25. https://doi.org/10.4028/www.scientific.net/KEM.391.1

[40] F. Xu, W. Zeng, D. Li, Recent Advance in Alkoxysilane-Based Consolidants for Stone. Prog. Org. Coat. (2019) 127: 45-54. https://doi.org/10.1016/j.porgcoat.2018.11.003

[41] S. Naidu, G. W. Scherer, Nucleation, Growth and Evolution of Calcium Phosphate Films on Calcite. J Colloid Interface Sci (2014) 435: 128137. https://doi.org/10.1016/j.jcis.2014.08.018

[42] R. van Hees, R. Veiga, Z. Slížková, Consolidation of Renders and Plasters. Mater Struct (2016) 50 (1): 65. https://doi.org/10.1617/s11527-016-0894-5

[43] S. W. Michalski, A Physical Model of the Consolidation Process, Particularly of Paintings in Proc. CESMAR7 Conf. Milan Novemb. 2006. (Milan, Italy), 2008, 27-47.

[44] G. Wheeler, Alkoxysilanes and the Consolidation of Stone. Getty Publications. 2005.

[45] X. Cao, W. Harris, Carbonate and Magnesium Interactive Effect on Calcium Phosphate Precipitation. Environ Sci Technol (2008) 42 (2): 436-442. https://doi.org/10.1021/es0716709

[46] J. Delgado Rodrigues, A. P. Ferreira Pinto, Laboratory and Onsite Study of Barium Hydroxide as a Consolidant for High Porosity Limestones. J Cult Herit (2016) 19: 467-476. https://doi.org/10.1016/i.culher.2015.10.002

[47] D. C. Montgomery, Design and Analysis of Experiments, 10th Edition. Wiley. 2019

[48] A. Miquel, P. Brombiet, V. Vergès-Belmin, L. Binda, G. Baronio, E. De Witte, H. De Clercq, R.P.J. van Hees, H. Brocken, Treatment with Substrates Loaded with Sodium Sulphate: Influence of the Physical Properties of the Substrates on the Salt Content Limit / Experimentelle Studie Zur Verträglichkeit Einer PolysiloxanBehandlung Mit Einem Porösen Natriumsulfathaltigen Werkstoff: Einfluss Der Physikalischen Eigenschaften Des Untergrundes Auf Den Kritischen Salzgehalt. Restor Build Monum (2001) 8: 271-292. https://doi.org/10.1515/rbm-2002-5666

[49] G. Graziani, E. Sassoni, G. W. Scherer, E. Franzoni, Phosphate-Based Treatments for Consolidation of Salt-Bearing Globigerina Limestone. IOP Conf Ser Mater Sci Eng (2018) 364: 012082. https://doi.org/10.1088/1757-899X/364/1/012082

[50] D. Costa, J. Delgado Rodrigues, Consolidation Treatment of Salt Laden Materials. Methodology for Their Laboratory Study. Proc 11th Int Cong Deterioration Conserv. Stone Ed. JW Kukaszewicz P Niemcewicz Torun. (2008): 827-836

[51] G. Caneva, M. P. Nugari, M. P. Nugari, O. Salvadori, Plant Biology for Cultural Heritage: Biodeterioration and Conservation. Getty Publications. 2008.

[52] T. Wangler, G. W. Scherer, Clay Swelling Mechanism in Clay-Bearing Sandstones. Environ Geol (2008) 56 (3-4): 529-534. https://doi.org/10.1007/s00254-008-1380-3

[53] G. W. Scherer, I. Jiménez-González, Characterization of Swelling in Clay-Bearing Stone. Geol Soc Am Spec Pap (2005) 390: 51-61. https://doi.org/10.1130/0-8137-2390-6.51
[54] C. Atzeni, U. Sanna, N. Spanu, Some Mechanisms of Microstructure Weakening in High-Porous Calcareous Stones. Mater Struct (2006) 39: 525-531. https://doi.org/10.1007/s11527-005-9044-1

[55] C. Félix, P. Ferrari, A. Queisser, Déconsolidation Par Absorption d'eau de Grès Traités Avec Le Silicate d'éthyle. Mesures Non Destructives de $\mathrm{E}, \mathrm{G}$ et v. in Proc Ninth Int Congr Deterioration Conserv Stone 2, Elsevier (Venice), 2000, 287-295.

[56] F. Caruso, T. Wangler, A. M. Aguilar Sanchez, H. Richner, J. Melchior, R. J. Flatt, Effect of Swelling Inhibitors and Self-Restraint on the Durability of Ethyl-Silicates Consolidants Applied to Clay-Bearing Stones in 12th Int Congr Deterioration Conserv Stone Columbia Univ (New York), 2012.

[57] I. Jiménez-González, R. J. Flatt, T. Wangler, Factors Affecting Portland Brownstone Durability. Lambert Academic Publishing. 2012.

[58] F. Girardet, Maison Tavel, Renforcement de La Pierre à l'ester de Silice. Procédure d'impregnation et d'application (Protocole). RINO Sàrl. 2007.

[59] E. Franzoni, E. Sassoni, Comparison Between Different Methodologies for Artificial Deterioration of Stone Aimed at Consolidants Testing in Proc. 12th Int Congr Deterioration Conserv Stone NY (New York City, USA), 2012, 22-26.

[60] B. Lubelli, R. P. J. van Hees, T. G. Nijland, J. Bolhuis, A New Method for Making Artificially Weathered Stone Specimens for Testing of Conservation Treatments. J Cult Herit (2015) 16 (5): 698-704. https://doi.org/10.1016/i.culher.2015.01.002

[61] C. L. Searls, L. Binda, J. F. Henriksen, P. W. Mirwald, A. Nappi, C. A. Price, K. E. P. Van Balen, V. Vergès-Belmin, E. Wendler, F. H. Wittmann, Group Report: How Can We Diagnose the Condition of Stone Monuments and Arrive at Suitable Treatment Programs? In: Sav our Archit Herit Conserv Hist Stone Struct Rep Dahl Workshop Sav our Archit. Heritage-Conservation Hist Stone Struct, March 3-8 1996. John Wiley \& Sons, Ltd, 1997, 199-221.

\section{Supplementary bibliography}

\section{Chemistry and Physical Chemistry of Consolidants}

C. V. Horie, Materials for Conservation, 2nd Edition. London: Routledge, 2013.

C. J. Brinker and G. W. Scherer, Sol-gel science: the physics and chemistry of sol-gel processing. Academic press, 2013.

L. Klein, M. Aparicio, and A. Jitianu, Eds., Handbook of Sol-Gel Science and Technology: Processing, Characterization and Applications, 2nd ed. Springer International Publishing, 2018.

P. Baglioni and D. Chelazzi, Nanoscience for the Conservation of Works of Art. Royal Society of Chemistry, 2015.

G. Kyzas and A. C. Mitropoulos, Novel Nanomaterials: Synthesis and Applications. London: IntechOpen, 2018.

S. Dorozhkin, Hydroxyapatite and Other Calcium Orthophosphates: Biocomposites, Self-Setting Formulations and Dissolution, 2017.

\section{Health \& Safety}

C. Hawks et al., Eds., Health and Safety for Museum Professionals, 1st edition. Society for the Preservation of Natural History Collections, 2010.

American Institute for Conservation of Historic and Artistic Works. Health \& Safety Committee Conservation Wiki. Available at http://www.conservation-

wiki.com/wiki/Health_\%26_Safety\#Health_.26_Safety_Committee Conservation Wiki 